\title{
An Examination of Instructional Approaches in Online Technical Education in Community Colleges
}

\author{
Brian S. Horvitz, Ph.D., Lisa R. Garcia, and Regina Garza Mitchell, Ed.D. \\ Western Michigan University \\ Cheryl D. Calhoun, Ph.D. \\ Santa Fe College
}

\begin{abstract}
Technical education programs in community colleges prepare students for many science and engineering-based jobs in the United States. An increasing number of technical education programs in community colleges are using online learning tools to teach courses. However, little is currently known about the ways these programs are integrating online learning in their coursework. This study examined fifteen National Science Foundation funded technical education programs that use online learning to partially or entirely deliver their courses. We conducted semistructured interviews with key personnel from each project. Through analysis of this data, we found that these technical education programs used a variety of instructional delivery approaches that can be categorized as follows: (a) a hybrid or blended course with asynchronous online lectures; (b) a hybrid or blended course with synchronous lectures; (c) a hybrid or blended course with a combination of asynchronous and synchronous lectures and discussions; or (d) a course that is fully online. We also found that these online or hybrid technical education programs used a variety of different methods to give students experience in their field of study that can be categorized as follows: (a) pre-recorded video; (b) live video; (c) simulations; (d) equipment at home; (e) equipment in lab; and (f) professional site experience. We recommend that future research examine how well these approaches are working, incorporate student perceptions, and incorporate the views of employers of these programs' graduates.
\end{abstract}

Keywords: technical; higher education; STEM; two-year college; hybrid

Horvitz, B.S., Garcia, L.R., Garza Mitchell, R., \& Calhoun C.D. (2019). An examination of instructional approaches in online technical education in community colleges. Online Learning, 23(4), 237-252. doi:10.24059/olj.v23i4.1613

\section{An Examination of Instructional Approaches in Online Technical Education in Community}

Community colleges have been instrumental in helping students develop the knowledge and technical skills they need to be successful in today's labor market (Carnevale, Smith, \& Strohl, 2013). Technical education, also called vocational education, prepares students for jobs as technicians in largely science and engineering-based fields such as manufacturing technology, agricultural and bio-technologies, energy and environmental technologies, information technologies, and security technologies. The United States Department of Education (2012) noted 
that modernizing technical education is essential in bolstering our educational system and increasing economic outcomes in the country. The same report described how online learning can help to increase technical education opportunities for students in rural and remote communities. Community colleges were early adopters of online education, and they continue to experience the greatest amount of growth in that area (Allen \& Seaman, 2016; Lokken, 2018).

Despite the continued growth of online education at community colleges, the bulk of the literature focuses on online education in entry-level general education or liberal arts courses. Few studies have examined how online education is incorporated into technical education. The majority of empirical work in this area was produced before 2010, and we draw on it because it provides the small baseline about what is known. This study adds to the literature base by sharing the findings of an exploratory study of online integration into technical education at community colleges.

\section{Review of Literature}

\section{Technical Education}

Technical education has played a prominent role in community colleges and is taking on even more importance. Technical education is increasingly seen as a profitable resource for community colleges, states, and the private sector, as well as a solution for boosting degree completion (e.g., D’Amico, 2016; Harrison, et al., 2006; Robinson \& Christophersen, 2008) and a stimulus for the economy (D'Amico, Morgan, Katsinas, \& Friedel, 2015; U.S. Department of Education, 2012). Jobs requiring technical degrees are one of the largest growing markets (Jepsen, Troske, \& Coomes, 2014; U.S. Department of Labor, 2014) and this trend continues. Jobs requiring technical education and training are viewed as a gateway to the middle class and require education at the associate degree or certificate level (Carnevale, Jayasundera, \& Hanson, 2012). The importance of technical education was reinforced by U.S. federal efforts such as the White House's (2009) call for an additional 5 million graduates from community colleges by the year 2020. To help achieve this goal, over $\$ 2$ billion was allocated to fund community college and industry partnerships through the Trade Adjustment Assistance Community College and Career Training (TAACCCT) program (Plotkin, 2011; The White House, 2014).

Over the past ten years, technical education has had to transform itself in order to meet the increase in skills and knowledge that employers demand as well as the complexities of today's economy (Kreamer \& Zimmerman, 2016). In addition, industries require robust skill sets that surpass vocational instruction to include soft skills such as socialization, teamwork, organization,

and time management (Benson, et al., 2005; Carnevale et al., 2013; Hora, Benbow, \& Oleson, 2016 Lynch, 2000). This transformation resulted in a shift from mere job preparation to a model that combines technical skills for career preparation with domain-specific concept and knowledge learning (Kreamer \& Zimmerman, 2016).

Much of this technical education grew within community colleges as part of the "new vocationalism" movement in the early to mid-1990s (Mars, 2013). In response to increasing demands for high-skilled workers, community colleges moved toward offering programs that prepared students for mid-level technical and managerial skills sets that are valued in an increasingly knowledge-based economy. 
Although little research has been conducted on the instructional practices of technical education, one study found that technical faculty members "most frequently use the instructional strategies of interactive lecture, questioning, whole-group discussion, and guided practice in their courses" (Fletcher, Djajalaksana, \& Eison, 2012, p. 80). These practices align with a conventional one-to-many approach used in traditional face-to-face classes in which instructors transmit information to students (Hanna, 2003). Methods of instruction are an important consideration when planning and investigating online education, which favors more constructivist approaches that involve instructors connecting asynchronously with students who then interact with both instructors and other students in collaborative ways (Garrison, Anderson, \& Archer, 2010; Hanna, 2003; Major, 2015).

\section{Online Learning in Community Colleges}

Online education in community colleges, the setting for much technical education, is not a new phenomenon. Allen and Seaman (2016) report that $45 \%$ of all online enrollments at public institutions are in community colleges. For the purposes of this project, we define online, hybrid, and web-enhanced courses using definitions provided by the Instructional Technology Council: online courses are those in which $80 \%$ or more of a course is delivered online; hybrid courses are those in which $30-79 \%$ of content is delivered online; web-enhanced courses are those which incorporates online elements to facilitate no more than $29 \%$ of the class (Lokken \& Mullins, 2014). The National eLearning Survey of Community Colleges by the Instructional Technology Council (ITC) (Lokken, 2018), an affiliate council of the American Association of Community Colleges, found that online enrollment in community colleges increased $8 \%$ from the Fall of 2015 to the Fall of 2016. In its review of 2014-2016 enrollment, this report found that "community college students $(30.9 \%)$ were more likely than undergraduates at four-year public institutions $(29 \%)$ or four-year private colleges $(25.6 \%)$ to be enrolled in at least one online class" (Lokken, 2018, p. 7). Growth in enrollment and offerings indicates that online education, in various formats, will continue to play an important role for community colleges.

Traditionally, an instructor was solely responsible for his or her course and course material, but online education changed the faculty role. In some cases, courses became productions that were the result of specialists in the form of instructional designers and multimedia professionals working with faculty, whose role became that of "content expert" (Hanna, 2003; Smith, 2010). In others, faculty performed dual roles as both faculty and instructional designers and struggled with adapting and conceptualizing their courses for the online environment (Buckenmeyer, Hixon, Barczyk, \& Feldman, 2011). Hence, colleges are forced to examine and, perhaps, alter their views of teaching, learning, and the faculty role.

The shift toward online education, and in particular online technical education, provides challenges for administrators and faculty. Such programs have historically used "hands-on" apprenticeship-style teaching (Pratt, 1998). The very nature of this hands-on tradition makes technical education the most challenging to deliver in an online format due to lab-based components and apprenticeship models that are time-consuming, challenging to replicate, and require coordination and buy-in from multiple constituents (Author, 2011). Unfortunately, there is a dearth of published research on the ways technical education programs are using online learning tools and environments. There are few case examples and little guidance in the literature that can help technical education leaders and educators make informed decisions as they work to create or improve online learning options for their programs. 
To begin to fill this gap in the literature, we conducted a research study, funded by the National Science Foundation's (NSF) Advanced Technological Education (ATE) program (award \#1501794), that examined other NSF-funded technical education projects in community colleges that incorporate online learning as a key instructional component. We investigated how online learning is being implemented and integrated into community college technical education programs that have traditionally been classroom-based. The research reported here is subset of this larger study that examined online learning components, impacts on students, and impacts on faculty. following:

Our guiding research questions for the portion of our study described here were the

How have online learning components been integrated into technical education in funded ATE projects?

a. What is the nature of the courses being developed? (e.g., fully online, hybrid, web enhanced)?

b. How do students gain "hands on" experience in partially or fully online technical education programs?

To answer these questions, we designed a study intended to examine a set of community college technical education programs that use what we determined to be a significant amount of online learning (we describe below how we determined what programs to include). To accommodate the needs and interests of our study's funding source, the NSF, we focused the pool of potential programs to current or recent recipients of NSF-ATE funding. The NSF could then learn about how their funding is contributing to innovations in online technical education.

\section{Method}

\section{Data Collection}

A review of five years of funded projects from 2010-2014 identified 38 possible sites for inclusion in the study. We asked the primary investigator (PI) from each of the 38 NSF project sites to participate in our study. We ultimately got participation from 17 projects, and 15 of those cases are examined here. Two cases were eliminated because we learned they did not focus on community college technical education programs. For the remaining 15 projects, we interviewed one or two key personnel: the PI from each project and in some cases, a second person from the project, either a co-PI or an instructor that worked on the project.

For our research project, we developed a semi-structured interview protocol. We opted to use semi-structured interviews to allow for questions that may help elicit further meaning from participants (Merriam \& Tisdell, 2016). The interview protocol was tested and refined prior to being implemented. Each researcher conducted a sample interview with a community college faculty member who has implemented online education, but who was not a part of the study sample. The interview protocol was revised based on feedback from the sample interviewees to ensure questions were appropriate and relevant, as well as designed to obtain the kinds of information we sought. 
Items were included in the interview protocol that were written to address the research questions listed above. To learn about the "nature of the courses being developed," we asked these questions:

What elements of your course (e.g. lecture, assignment, discussion, etc.) are being taught online? What tools are being used for online courses and course elements (e.g., LMS, simulations, programs, assignments)? What elements are conducted in a face-to-face setting? What approaches are being used to teach content (e.g., active learning, collaborative learning, synchronous, asynchronous, etc.)?

To learn about how "students gain 'hands on' experience in an online environment," we included these questions in our protocol:

How do students gain "hands on" experience in your online environment? How do students learn the soft skills necessary for employment in your online setting?

Interviews were conducted by our project's co-PIs. We used an online audio-conferencing system called Zoom to conduct the interviews. This enabled us to use Zoom's recording functionality to create an audio file of each interview. Audio files were sent to a professional transcriptions service, providing us with an electronic text file of each interview.

\section{Data Analysis}

For this study, interview transcripts were coded by all of our research team members. One of the foci for our coding was what we termed "instructional delivery approach". This included discussion of what modes of instruction programs used such as fully online instruction, hybrid, or face-to-face. We also looked for discussion of the specific instructional tools and strategies programs used such as video, types of lab work, and simulations. We termed these "types of educational experience". Each transcript was analyzed by a minimum of two researchers, and the research group had regular discussions to ensure codes and themes accurately described the findings.

As a group, we identified multiple themes relevant to the use of online learning technologies in technical education including those related to the research questions listed above. In the Results section below, we explain what themes we identified as a group under both of the foci listed above: instructional delivery approach and types of educational experience. We describe the ways each of these themes was found to be present in the technical education programs we investigated.

\section{Results}

\section{Instructional Delivery Approach}

Online learning in CTE can be delivered in different ways. Often, courses are offered in a hybrid or blended mode, which combines traditional face-to-face learning in a classroom, along with live e-learning and self-paced online learning (Hoic-Bozic, Mornar, \& Boticki, 2009). Students can also learn either synchronously, where materials for the course are presented live and in real time (Phelan, 2015) or asynchronously, where "material is archived and then available anytime, anywhere" (Phelan, 2015, p. 257). The type of instructional delivery and online course content for the programs examined in this study fell under four categories: (a) a hybrid or blended course with asynchronous online lectures; (b) a hybrid or blended course with synchronous 
lectures; (c) a hybrid or blended course with a combination of asynchronous and synchronous lectures and discussions; or (d) a course that is fully online.

Nine of the 15 projects in this study used a hybrid mode for instructional delivery with asynchronous online lectures, such as online lectures and modules. For example, one renewable energy project enabled instructors to record "whiteboard" lectures (where the instructor walks through steps drawn out on a whiteboard) and post the videos on YouTube, where students could view at a time that best fit their schedules. This asynchronous learning was accompanied by a synchronous face-to-face lab. In an advanced manufacturing program, all of the coursework was located online and included video demonstrations embedded in PowerPoint presentations. The students were able to go through the online components of the class and once they felt they were ready, came to campus and connected with faculty in the laboratory and showed instructors their finished projects. Lectures and modules were also placed online for a biomanufacturing project. Students completed online modules on their own time, and then went through the modules together with their instructor in class. Another example included a sustainable energy project which used online lectures and after viewing, students would then come in for in-person labs.

Although not as common as the courses with asynchronous lectures, four of the 15 projects used a hybrid mode with synchronous lectures, which either occurred face-to-face or through the use of video conferencing software, such as GoToMeeting. A cybersecurity project used video conferencing as well as in-person labs to connect with students, and the class offered virtual internships as well. Another project dealing with robotics and advanced manufacturing used synchronous in-class discussions, lectures, and labs while also providing videos and PowerPoint presentations for students online asynchronously. A vacuum technology project offered lectures via telepresence interspersed with demonstration and lab activities, while at the same time offering readings, study guides, and quizzes online.

There was one project that offered a combination of both asynchronous and synchronous lectures and discussion. This winemaking project utilized video conferencing for students and instructors so that they could have synchronous discussions and presentations. However, the program also made use of prerecorded lectures for students to view on their own time asynchronously. The program also required students to perform field hours at either a vineyard or a winery. This unique blend of asynchronous and synchronous lectures allowed students to benefit from both types of learning. Whether the courses used asynchronous or synchronous lectures, though, almost all of the projects studied used a hybrid or blended learning approach. This supports the notion of blended learning as an "increasingly popular form of e-learning" (HoicBozic, Mornar, \& Boticki, 2009, p. 19).

Finally, one project we examined was offered entirely online. This cybersecurity learning project was offered in a mostly asynchronous online environment and made use of virtual machines for both online hands-on assignments as well as online labs. Students participated in online discussions and were also required to record their progress and document their completion in a virtual notebook. Students could also choose, however, to meet synchronously with their peers for online collaboration and activities. This course may have been easier to implement fully online due to the nature of the subject matter since cybersecurity work is primarily done in a networked computer environment, so students only need a networked computer to have access to something approaching a professional environment. 


\section{Types of Educational Experience}

Many of the skills taught in technical education programs are hands-on in nature. Students frequently learn skills that require the manual use of tools and machinery. This creates a challenge for programs that are developing online or hybrid courses. How do these programs ensure that their students get the practice they need to develop and hone these hands-on skills? To learn about this, we asked our interviewees about the modes of instruction they used in their online or hybrid courses and programs. In particular, we examined the strategies and tools used to give their students direct or vicarious experience performing technical skills and procedures. We identified six different strategies technical education programs used to give students such experience: prerecorded videos, telepresence (real-time, live video), computer-based simulation, use of equipment in students' home, use of equipment in a lab, and real experience at a professional site. Each of these strategies falls along a continuum of concrete to abstract experience, as described by Edgar Dale (1969) in his seminal writing on the Cone of Experience. The Cone of Experience is a visual representation of the progression of potential learning experiences ranging from direct, purposeful experience, or learning by doing (hands-on or simulated experience) to more iconic experiences, or learning through observation (live or video demonstrations), and finally to more symbolic experiences, or learning through abstractions (reading). Pre-recorded videos and telepresence are both examples of learning through observation. Computer-based simulation, use of equipment in students' home, use of equipment in a lab, and real experience at a professional site are examples of learning by doing. Examples of each of these strategies are listed in Figure 1.

Eight of the projects in this study used pre-recorded videos as a learning-throughobservation tool. In an advanced manufacturing program, all skill demonstrations were video recorded and shared with students online. These students then came to campus and applied what they have learned from the videos through practice on actual equipment. Another program that focused on building the math skills of students in rural communities used videos to flip the classroom, a strategy in which teachers move more traditional direct instruction outside of the classroom. Students watched instructional videos on their own time, allowing them to use inperson classroom time to ask questions and work through problems with the instructor. In both of these examples, because the videos were pre-recorded, students could watch them, pause them, and rewind them as many times as necessary to meet their learning goal. 


\section{Pre-recorded Video}

- Online videos used to supplement course material

- Use of streaming videos to supplement course content

-Whiteboard lectures posted on YouTube

-Didactic portion of courses moved online and used videos to appeal to working students

-Students used screen-casting tools to record and share their projects; instructors used screen-casting to share lessons

-Instructors used video-lectures and screencasting videos for students to watch online -All instructor demonstrations were videotaped and posted online with PowerPoint presentations

-YouTube videos were used to share some content with students

\section{Equipment at Home}

- Cybersecurity labs done on networked home computers

-Winemaking and tasting kits in a box -Work at home on sustainable technology lab kit in preparation for two week lab training on campus or at mobile training lab

\section{Simulation}

- Developed own simulations to give students feel of industrial or workplace settings -Students used NETLAB, a virtual sandbox system for practice

-Students used online simulation games to help them learn and understand complex building projects

\section{Equipment in Lab}

-Didactic portions of the courses were online while the labs were in person on campus -Moving lectures online allowed much more time for hands-on labs on campus demonstration and lab activities - Most students did physical lab on campus with help from lab techs

- Trainer equipment which replicates most functionality of professional equipment was made available for students to practice on and learn

-Students could access the servers they needed to complete their labs on campus - After their home kit labs, students participated in a two week intensive lab session on campus or at the program's mobile solar training lab

-Students viewed lectures online and came on campus one day per week for lab work

\section{Telepresence/Live Video}

-Video conferencing for discussions and presentations

-High definition telepresence used to demonstrate expert use of professional equipment

\section{Professional Site}

-Provided students with virtual internships in which students worked with industry mentors remotely, using weekly video conference calls -Set up student internships at area employers to help them get professional experience -Students did a field practicum at a local vineyard or winery to receive professional experience

Figure 1. Examples of Strategies Used to Give Students Experience 
Live video, or telepresence, was used as a learning-through-observation tool by one program and as a real-time remote discussion tool by one other program. A vacuum technology program used high-definition telepresence technology that allowed students in a select set of remote locations around the country to watch expert instructors demonstrate how to use expensive professional equipment. Since these were live demonstrations, students were afforded the opportunity to have the instructor show or operate some aspect of the equipment they might not have otherwise. Students were also able to ask questions or request clarification from the instructors in this interactive telepresence environment. The winemaking and viticulture program use real-time online video for group discussions to supplement the online asynchronous discussions in some courses.

Computer-based simulations provided a learning-by-doing tool in five projects. One of the cybersecurity programs we examined used simulations to give students practice, in addition to the practice they received during the in-person components of their hybrid courses. Cyber security is a computer-based field, so the simulations in this program were not intended to give students access to equipment they could not otherwise access. Rather, these simulations gave students repeated practice that helped in skill-building. In contrast, a bio-manufacturing program used a program to simulate use of technical equipment they would not otherwise have access to at home. Both of these examples demonstrate how simulation can be used to provide students with repeated practice performing a skill, though not on actual professional equipment.

In order to enable learning-by-doing, students in five programs used technical equipment at home. In a sustainable energy technology program, students conducted a series of labs at home with equipment they purchased on their own, such as temperature sensors and solar energy kits. These labs helped students prepare for a two-week intensive practicum at the school's campus. In another cybersecurity program, students were able to use a home computer connected to the Internet to access a remote server, which was identical to the type of server they would use professionally. This afforded students the opportunity to do assignments and practice skills on actual equipment from home.

We found seven projects that enabled learning-by-doing by allowing students to work on technical equipment at a laboratory. In a hybrid photonics program, students worked on modularized courses online and then completed the lab portions of their courses on campus, where they received support from expert instructors. This allowed them to learn and practice on expensive professional equipment that would have been hard to access otherwise outside of an industrial setting. The vacuum technology program gave students opportunities to practice on trainer equipment, which was essentially a replica of the equipment they will eventually use professionally. These trainings? are expensive to produce, so only a few of them were produced for the handful of national sites where students enrolled in their program at a distance.

Finally, three of these programs permitted students to work in actual professional settings as a way to enable learning-by-doing. One of the cybersecurity programs had its students participate in what they call "virtual internship" or an "intern/extern" model. Students worked for technology companies but were able to do so from their homes. They received supervision and support from supervisors via videoconferencing and by loading their issues onto a shared wiki. In contrast, a winemaking and viticulture program required students, who were scattered across the country, to conduct field hours at actual professional settings near them, such as wineries or vineyards. Some students in this program already worked in such a setting, while others worked with the program to identify a setting where they could perform these field hours. 


\section{Discussion}

\section{Instructional Delivery Approach}

In examining the ways that online learning has been integrated into technical education we found that most of the fifteen programs we examined were online/face-to-face hybrids and utilized asynchronous interactions in their courses. This finding is in-line with Watts' (2016) assertion that, "Although asynchronous has been the primary method for interacting in the online setting, technological advancements have made it possible for students and instructors to interact in a more face-to-face like setting" (p. 30). One likely reason asynchronous learning is more prevalent in online learning is that it provides students with a more flexible and self-paced learning environment (Skylar, 2009). Many of the program directors we interviewed discussed self-pacing and flexibility as a rationale for using asynchronous instruction. One program director mentioned that many of the students were working professionals - commonplace in technical education programs - and were not able to attend an in-class lecture, so the asynchronous lectures worked better for them. Another interviewee talked about the benefit of students being able to go back, pause, and review lectures as a way of self-learning.

There are benefits to asynchronous learning for the instructors as well. According to one director, asynchronous learning allows instructors to give more content exposure to students that need additional extra time without slowing down the class for people that are able to grasp the material immediately or more quickly. Asynchronous learning, according to another interviewee, also frees up the instructor to have higher-level conversations with students because they were able to learn the material on their own time. Due to its potential benefits for both the student and instructor, it is not surprising that asynchronous learning is found in many technical education programs.

We also found programs that used synchronous lectures for students. One of the program directors in this study stated that for certain subjects, such as mathematics, students tend to grasp the material better if they have more face-to-face interaction with their instructors, so it made sense to have synchronous instruction in the course. Synchronous learning can also be helpful to instructors, as synchronous delivery allows instructors to assess student learning in real-time and help them to tailor the material accordingly (Schullo, Hilbelink, Venable, \& Barron, 2007). One director stated that instructors need to be able to read the body language of the students and determine if they are confused and need additional help. Another director who used asynchronous learning in her program spoke about how she felt that synchronous learning better enabled instructors to help a student immediately and was pushing to have more synchronous instruction in her program. An interviewee who used synchronous telepresence in his program talked in depth about the sophisticated technology used, from multiple cameras to a 75-inch monitor that allowed the cameras to zoom in so the students could view highly technical demonstrations. While this program had the funds to purchase advanced technological equipment, more programs may not use synchronous learning due to expense as well as investment in technical infrastructure, faculty development, and technical competencies of students (Olson \& McCracken, 2015).

\section{Types of Educational Experience}

The findings from this study of fifteen technical education programs show that such programs are offered, at least in part, at a distance, and use a variety of different instructional strategies to help students develop professional skills. As discussed in the Results section, some of these strategies reflected a learning-through-observation approach while others reflected a 
learning-by-doing approach, with some variety within each general category. As researchers, we are interested in understanding what factors may drive the decisions to use these various instructional strategies. One factor we looked at was accessibility or scarcity of the equipment students are learning to master. Four of the projects examined here help illustrate this dynamic.

The vacuum technology program trains its students to use equipment that will only be found in high-tech industry settings, making it relatively scarce. Their solution was two-pronged: 1) investing heavily in a state-of-the-art telepresence system so students can watch an expert instructor operate live equipment, and 2) investing heavily in the creation of a few equipment "trainers," high fidelity replicas of the actual equipment on which students can practice, which were shipped to select remote sites around the country.

Second, there was the winemaking and viticulture program. The equipment they train their students to use can be found at wineries and vineyards all over the country, making it accessible to someone who can work or intern at one of these businesses in their geographical area. The equipment is large and expensive. Given such accessibility at local businesses, the program required its students to perform field hours at local wineries or grape farms.

Third, there was the renewable energy program. The program used online videos to move the didactic portion of instruction out of the classroom. This allowed students to spend face-toface time in the school lab where they could get hands-on experience using professional equipment like amp, volt, and ohm meters. The equipment was not hard to obtain and did not require a large investment, so it was easy to purchase equipment specifically for the program and make it available for students to become familiar with and practice on at the lab.

Fourth, there were the cybersecurity programs. In the field, the primary equipment students are trained to use is computers. Since most, if not all, students in these programs have personal computers, students were able to get hands-on professional training from home or anywhere with an Internet connection.

These four programs reflect a range of accessibility to professional equipment on which students can learn and practice. This accessibility may impact where these programs fall on a continuum of fully online to hybrid to face-to-face learning. The only program that chose to go completely online was one of the cybersecurity programs. This was possible because, as stated above, the only professional equipment they need to learn to use is computer-based and students have access to their own computers. All the other programs chose to design some type of a hybrid program. The renewable energy program was able to create a mostly online program in which face-to-face time was used for students to get hands-on practice on equipment that is easy for anyone to obtain. Because the winemaking and viticulture program trained students on equipment that is widely accessible in many geographically dispersed businesses, the majority of their program was online with only required field hours and some wine tasting happening face-to-face. The vacuum technology program, however, required significantly more face-to-face time for students in the form of practice on trainer equipment and the need to go to a classroom for telepresence sessions because of the limited accessibility, or scarcity of the equipment in their field.

As stated above, one program examined here made coursework entirely online. It was one of the cybersecurity programs in which students were learning to use equipment that is entirely software-based. All the other programs incorporated some actual hands-on instruction or lab work during which students could use professional equipment or a close facsimile of it. It seems the 
leaders of the programs examined do not believe that traditional hands-on learning and experience can be completely replicated online. Related to this, they may be concerned about their students being prepared to go into professional settings and be ready to work on actual professional equipment. These seem like logical concerns that might prevent a complete transition to entirely online instruction in most technical fields.

\section{Conclusion}

For this study, we reviewed 15 NSF ATE projects in order to understand how online learning was being integrated into those technical education programs. We found there were projects that used a hybrid mode of instructional delivery and complemented the courses with either asynchronous or synchronous lectures and discussion. There were also a variety of instructional strategies adopted by the programs, which ranged from learning-through-observation to learning-by-doing, depending on the type of program.

There are important implications for practice gleaned from this study. The first deals with terminology. While we identified these technical education programs because of their significant use of online learning tools and environments, almost all of these programs are hybrid in nature. After more than 20 years of offering online education, terminology used to describe online versus hybrid versus web-enhanced courses remains an issue. It is important that programs clearly articulate the instructional delivery approaches they use so students can determine how well a program will meet their needs in terms of flexibility and preferred learning style.

A second implication is for the people responsible for implementing these programs. As described here, programs are getting creative in the ways they are using a variety of online tools and blending them with face-to-face experiences to meet students' needs and the programs' goals. These hybrid environments are likely different than those most instructors have previously taught in or that their students have learned in. Programs moving in this direction will benefit from investing resources in training related to teaching in online and hybrid environments as well as supporting students as they learn how to succeed in such environments. It was clear from the participants in this study that instructional design assistance is also a key support mechanism for faculty. Faculty struggle with technical and design aspects of courses and having supported instructional design also provides continuity in regard to what students can expect when they take these courses.

A third implication deals with the design of such innovative technical education programs. It is critical that programs consider the nature of the content they teach and the kinds of equipment and machinery they are training students to master as they make educational design decisions (Horvitz, 2018). While programs focused on fields like cybersecurity which are largely computerbased may transition smoothly to an online environment without need for extensive capital investment, programs focused on fields that are more heavy machinery-focused like vacuum technology or robotics may need to invest heavily in the development training tools such as simulators or high definition telepresence equipment.

One solution is unlikely to fit all technical education programs, and programs must consider budget, ongoing costs, and the needs of their students when making these decisions. State funding for colleges continues to decline and has not risen to pre-recession levels (Katsinas, D'Amico, Friedel, Adair, Warner, \& Malley, 2016) and the cost of maintaining technical program 
equipment (physical or virtual) continues to rise. Hence, the fourth recommendation for practice is that programs and institutions should consider partnerships in order to grow programmatic offerings and share costs. Each of the programs we studied was involved in a partnership because it was part of their grant requirement. However, each also demonstrated an ability to produce more or better content and to reduce costs at individual colleges. Partnering with high schools created a much-needed pipeline of students who would potentially enter and complete their degree at the college and partnering with universities opened a pipeline for students to continue on to earn bachelor's and even master's degrees. Some colleges partnered with industry to either provide equipment (physical or simulations) and/or to further workers' education. Other partnerships involved multiple community colleges sharing didactic content portions online to allow students to complete a degree that might not otherwise be available at their institution. Considering partnerships from multiple partners and directions opens doors for colleges and, more importantly, for students.

Our review of the NSF ATE projects underscores the need for further research in a few areas. The grant funding received from the NSF could have played a factor in the decision-making of each program's instructional design, so we recommend future research focus on how programs not funded by the NSF are integrating online components into technical education programs. We also recommend that future studies examine how well these types of programs are performing. Researchers could begin to collect student performance data in order to help other technical education programs make better informed decisions. Also, student perceptions of these programs would be an important area to explore in the future because it would add an important dimension that can shed light on how these innovative online learning strategies are being experienced and if they meet students' needs. Future research should focus on how and what students are experiencing and learning which can inform decisions about the best ways to design these technical education programs. Finally, future research that incorporates interviews with employers to examine their perceptions of student learning would also benefit the field. Insight from these key stakeholders would be valuable as they are the ones who will eventually hire these students upon graduation. It is our hope that future research could lead to major improvements as well as shed much needed insight on the best ways to incorporate online learning in technical education.

\begin{abstract}
About the Authors
Brian S. Horvitz, Ph.D. is an associate professor of Educational \& Instructional Technology at Western Michigan University in Kalamazoo, Michigan. Lisa R. Garcia is a doctoral student in Higher Education Leadership at Western Michigan University in Kalamazoo, Michigan. Regina Garza Mitchell, Ed.D. is an associate professor of Higher Education Leadership in Higher Education at Western Michigan University in Kalamazoo, Michigan. Cheryl D. Calhoun, Ph.D. is Dean of Access \& Inclusion for Santa Fe College in Gainesville, Florida.
\end{abstract}




\section{References}

Allen, I. E. \& Seaman, J. (2016). Online report card: Tracking online education in the United States. Retrieved from http://onlinelearningsurvey.com/reports/onlinereportcard.pdf

Benson, A. D., Johnson, S. D., Taylor, G. D., Treat, T., Shinkareva, O. N., \& Duncan, J. (2005). Achievement in online and campus-based career and technical education (CTE) courses. Community College Journal of Research and Practice, 29(5), 369-394. doi:10.1080/10668920590921589

Buckenmeyer, J., Hixon, E., Barczyk, C. C., \& Feldman, L. (2011). Invest in the success of online programs at the university? Mentor professors. Contemporary Issues in Education Research, 4(6), 1-6.

Carnevale, A. P., Smith, N., \& Strohl, J. (2013). Recovery: Job growth and education requirements through 2020. Washington, DC: Georgetown Public Policy Institute, Georgetown University. Retrieved from: https://cew.georgetown.edu/wpcontent/uploads/2014/11/Recovery2020.FR_Web_.pdf

Carnevale, A. P., Jayasundera, T., \& Hanson, A. R. (2012). Career and technical education: Five ways that pay along the way to a B.A. Washington, DC: Georgetown Public Policy Institute, Georgetown University. Retrieved from: https://1gyhoq479ufd3yna29x7ubjnwpengine.netdna-ssl.com/wp-content/uploads/2014/11/CTE.FiveWays.FullReport.pdf

Dale, E. (1969). Audiovisual methods in teaching (3 ${ }^{\text {rd }}$ ed.). New York, NY: Holt, Reinhart \& Winston.

D’Amico, M. M. (2016). Community college workforce development in the student success era. In M. B. Paulsen (Ed.), Higher Education: Handbook of Theory and Research, 31 (pp. 217-264.

Fletcher, E. C., Djajalaksana, Y., \& Eison, J. (2012). Instructional strategy use of faculty in career and technical education. Journal of Career and Technical Education, 27(2), 6983.

Garrison, D. R., Anderson, T., \& Archer, W. (2010). The first decade of the community of inquiry: A retrospective. Internet and Higher Education, 13, 5-9. doi:10.1016/j.iheduc.2009.10.003

Hanna, D. E. (2003). Organizational models in higher education, past and future. In M. G. Moore \& W. G. Anderson (Eds.), Handbook of Distance Education (pp. 67-78). Mahwah, NJ: Lawrence Erlbaum Associates, Publishers.

Harrison, H.D., Earnest, D., Grehan, L., Wallace, J. (2006). Executive summary: secondary and post-secondary career and technical education in Tennessee. The University of Memphis, TN: Sparks Bureau of Business and Economic Research. 
Hoic-Bozic, N., Mornar, V., \& Boticki, I. (2009). A blended learning approach to course design and implementation. IEEE Transactions on Education, 52(1), 19-30.

Hora, M. T., Benbow, R. J. , \& Oleson, A. K. (2016). Beyond the skills gap: Preparing college students for life and work. Cambridge, MA: Harvard University Press.

Horvitz, B.S. \& Zinser, R. (2011). Identifying the state of online instruction in National Science Foundation funded technical education programs at community colleges. International Journal of Instructional Technology and Distance Learning, 8(12), 33-44.

Horvitz, B.S. (2018). Extending the reach of technical education with distance learning. Community College Journal of Research and Practice, DOI:10.1080/10668926.2018.1507849

Jepsen, C., Troske, K., \& Coomes, P. (2014). The labor-market returns to community college degrees, diplomas, and certificates. Journal of Labor Economics, 32(1), 95121.

Katsinas, S. G., D’Amico, M. M., Friedel, J. N., Adair, J. L., Warner, J. L., \& Malley, M. S. (2016). Education's new normal: An analysis of national surveys of access and finance issues, 2011 to 2015. Tuscaloosa, AL: The University of Alabama Education Policy Center. Retrieved from http://edpolicy.ua.edu/research/

Kreamer, K.B. \& Zimmermann, A. (2016). Setting a new standard in the $21^{\text {st }}$ century: Career technical education and programs of study. In S. Andreason (Ed.) Developing CareerBased Training (pp. 5-11). Atlanta, GA: Federal Reserve Bank of Atlanta, Publisher.

Lokken, F. \& Mullins, C. (2014). Trends in elearning: Tracking the impact of elearning at community colleges. Washington, DC: Instructional Technology Council.

Lokken, F. (2018). Trends in eLearning: Tracking the impact of eLearning at community colleges. Columbus, $\mathrm{OH}$ : Instructional Technology Council.

Lynch, R. L. (2000). New Directions for High School Career and Technical Education in the 21st Century (Information Series No. 384). Washington, DC: Office of Educational Research and Improvement. Retrieved from: https://files.eric.ed.gov/fulltext/ED444037.pdf

Major, C. H. (2015). Teaching online: A guide to theory, research, and practice. Baltimore, MD: Johns Hopkins University Press.

Mars, M.M. (2013). Community college economic and workforce development education in the neoliberal and academic capitalist contexts. In J.S. Levin and S.T. Kater (Eds.) Understanding Community Colleges (pp. 217-230). New York, NY: Routledge.

Merriam, S. B., \& Tisdell, E. J. (2016). Qualitative research: A guide to design and implementation $\left(4^{\text {th }}\right.$ ed.). San Francisco, CA: Jossey-Bass. 
Olson, J. S., \& McCracken, F. E. (2015). Is it worth the effort? The impact of incorporating synchronous lectures into an online course. Journal of Asynchronous Learning Network, $19(2), 1-12$.

Phelan, J. (2015). The use of e-learning in social work education. Social Work, 60(3), 257-264.

Plotkin, H. (2011, January 20). New job training and education grants program launched [Blog Post]. Retrieved from http://www.whitehouse.gov/blog/2011/01/20/new-job-training-andeducation-grants-program-launched

Pratt, D.D. \& Associates. (1998). Five perspectives on teaching in adult and higher education. Malabar, FL: Krieger Publishing.

Robison, M.H. \& Christophersen, K.A. (2008). The economic contribution of Capital Community College: State of Connecticut. Moscow, ID: Economic Modeling Specialists Inc. Retrieved from https:/www.capitalcc.edu/wp-content/uploads/2016/05/InstitutionalResearch-The-Economic-Contribution-Of-CCC-2016-1.pdf

Schullo, S., Hilbelink, A., Venable, M., \& Barron, A. E. (2007). Selecting a virtual classroom system: Elluminate Live vs. Macromedia Breeze (Adobe Acrobat Connect Professional). MERLOT Journal of Online Learning and Teaching, 3(4), 331-345. Retrieved from http://jolt.merlot.org/vol3no4/hilbelink.htm

Skylar, A. A. (2009). A comparison of asynchronous online text-based lectures and synchronous interactive web conferencing lectures. Issues in Teacher Education, 18(2), 69-84.

Smith, V. C. (2010). Essential tasks and skills for online community college faculty. In R. L. Garza Mitchell (Ed.), New Directions for Community Colleges 150, Online Education (pp. 43-56). San Francisco, CA: Jossey-Bass.

The White House. (2009). Education: Knowledge and skills for the future. Retrieved from: https://obamawhitehouse.archives.gov/issues/education/higher-education/buildingamerican-skills-through-community-colleges

The White House. (2014). Higher education. Retrieved from The White House website: http://www.whitehouse.gov/issues/education/higher-education

U.S. Department of Education (2012). Investing in America's future: A blueprint for transforming career and technical education. Washington, DC: Author.

U. S. Department of Labor. (2014). Trade Adjustment Assistance Community College and Career Grant Training Program. Retrieved from https://doleta.gov/taaccet/

Watts, L. (2016). Synchronous and asynchronous communication in distance learning: A review of the literature. The Quarterly Review of Distance Education, 17(1), 2332. 